\title{
O Pibid como espaço de formação contínua: experiências, reflexões e perspectivas
}

\section{Pibid as a space for continuous training:}

experiences, reflections and perspectives

\section{El Pibid como espacio de formación continua:}

experiencias, reflexiones y perspectivas

\section{MARINETE DA FROTA FIGUEREDO*}

Universidade Estadual do Sudoeste da Bahia, Vitória da Conquista-BA, Brasil.

\author{
MARLON MESSIAS SANTANA CRUZ \\ Universidade do Estado da Bahia, Guanambi-BA, Brasil.
}

\begin{abstract}
RESUMO: O texto objetiva refletir acerca dos espaços de formação contínua no âmbito do Programa Institucional de Bolsas de Iniciação à Docência (Pibid), a partir do subprojeto Educação Física da Universidade do Estado da Bahia, Campus XII, que teve como bases orientadoras a Pedagogia Histórico-Crítica e a Perspectiva Crítico-Superadora. Os momentos de reflexão e de estudos viabilizados pelo programa foram significativos para a formação dos profissionais, ao fomentar a análise crítica e reflexiva acerca do campo de intervenção e suas práticas pedagógicas.

Palavras-chave: Pibib. Formação docente contínua. Educação Física.
\end{abstract}

\begin{abstract}
The text aims to reflect on the continuous training spaces within the Programa Institucional de Bolsas de Iniciação à Docência (Pibid), from the Educação Física subproject of the University of the State of
\end{abstract}

* Licenciada em Educação Física pela Universidade do Estado da Bahia (Campus XII) e mestranda em Educação pela Universidade Estadual do Sudoeste da Bahia. Atualmente é professora da Rede Municipal de Ensino de Guanambi-BA. E-mail: <marinetefrota@hotmail.com>.

* Licenciado em Educação Física pela Universidade do Estado da Bahia (Campus XII). Mestre em Educação e Contemporaneidade pela Universidade do Estado da Bahia (Campus I). Doutorando em Memória: Linguagem e Sociedade pela Universidade Estadual do Sudoeste da Bahia. Atualmente é professor da Universidade do Estado da Bahia (campus XII). E-mail:<marlonmessias@hotmail.com>. 
Bahia, Campus XII, which was based on Historical-Critical Pedagogy, and the Critical-Overcoming Perspective. The moments of reflection and studies made possible by the program were significant for the training of professionals, by encouraging critical and reflective analysis about the field of intervention, and its pedagogical practices.

Keywords: Pibib. Continuous teacher training. Physical education.

RESUMEN: El texto pretende reflexionar sobre los espacios de formación continua en el ámbito del Programa Institucional de Becas de Iniciación Docente (Pibid), del subproyecto de Educación Física de la Universidad del Estado de Bahía, Campus XII, Brasil, que tuvo como bases orientadoras la Pedagogía Histórica-Crítica y la Perspectiva Crítico-Superadora. Los momentos de reflexión y estudios que posibilitó el programa fueron significativos para la formación de profesionales, al fomentar el análisis crítico y reflexivo sobre el campo de intervención y sus prácticas pedagógicas.

Palabras clave: Pibid. Formación docente continua. Educación física.

\section{Introdução}

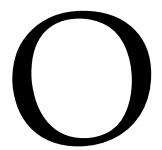

Programa Institucional de Bolsas de Iniciação à Docência (Pibid) constitui uma política de incentivo e de valorização do magistério, vinculada à Coordenação de Pessoal de Nível Superior (Capes), por intermédio da articulação entre a educação superior (a partir das licenciaturas) e as escolas da educação básica. Trata-se de uma iniciativa de formação de professores que projeta a inserção planejada, orientada e sistemática dos alunos de licenciatura em ambiente escolar, objetivando vivências e reflexões de situações concretas de ensino e aprendizagem no cotidiano escolar e na sala de aula.

Os discentes (bolsistas de Iniciação à Docência) são orientados por um professor da instituição em que estuda e também são acompanhados por um docente do ensino básico (PORTARIA CAPES 175, 2018). Por essa via de diálogos, como bem ressaltou Passos (2014), a escola e as ações pedagógicas tornam-se lócus e objeto de estudos coletivos, cujas reflexões alicerçadas na relação teoria e prática abrem espaço para uma formação crítica e reflexiva dos sujeitos envolvidos.

Esse trabalho coletivo envolve um movimento de trocas e análises constantes acerca do papel da escola, do docente, dos componentes curriculares, que permite o aprendizado não apenas ao licenciando, mas também ao professor que os acompanha na escola. Como co-formador, o professor supervisor orienta as ações pedagógicas, desde o processo de 
planejamento até a intervenção e também auxilia o contato do licenciando com a sala de aula. Ao participar de todo o processo como colaborador, esse profissional se envolve em debates, questionamentos, avaliações das práticas pedagógicas, estudos teóricos, os quais agregam conhecimentos e potencializam reflexões e análises da própria prática docente. Trata-se de vivências distintas, todavia, tanto os professores em formação, quanto os professores supervisores encontram-se em um processo dinâmico de aprendizagem, que tem como objeto de estudo as práticas pedagógicas sobre a realidade concreta.

Dessa maneira, embora o Pibid não seja especificamente direcionado à formação contínua de docentes, ao fomentar a reflexão a todos os envolvidos como foi destacado por Vergopolan e Mattos (2013), torna-se um espaço de formação crítica e de construções conjuntas que estimulam o professor do ensino básico a pensar continuamente sobre as múltiplas questões relacionadas ao trabalho docente, à área de ensino que atua, bem como ao papel da escola à sociedade. Assim, o programa pode contribuir para a diminuição das lacunas decorrentes da pouca oferta de formação continuada no país, sobretudo, na área de Educação Física, pois, como mostra a pesquisa de Bagnara (2014), os professores desse componente curricular ainda encontram muitas dificuldades para dar continuidade aos estudos, principalmente aqueles que moram longe dos grandes centros acadêmicos. A pesquisa também evidenciou que, geralmente, a oferta de cursos não contempla as questões pertinentes à Educação Física escolar, uma vez que é direcionada à intervenção nos espaços de atuação não escolares.

Considerando tais questões, o presente texto tem como objetivo refletir acerca dos espaços de formação contínua no âmbito deste programa, a partir das ações e experiências viabilizadas pelo subprojeto intitulado "Educação Física na escola: fundamentos e propostas em uma perspectiva crítica" referente ao Edital CAPES no 07/2018, que foi desenvolvido no curso de Licenciatura em Educação Física, da Universidade do Estado da Bahia (UNEB), Campus XII, entre agosto de 2018 e janeiro de 2020.

A relevância dessas reflexões está na pertinência da problematização das questões que nele se expõem e, também, serve como uma colaboração à práxis metodológica da área a qual pertence. $\mathrm{O}$ texto foi organizado em três etapas seguido das considerações finais. A primeira delas tem como intuito apresentar as questões que impulsionaram a elaboração e a idealização do projeto, bem como as expectativas depositadas nele. A segunda etapa é direcionada para uma breve apresentação dos caminhos metodológicos e a terceira etapa é voltada para a apresentação e reflexão acerca dos desdobramentos do subprojeto e os espaços de formação contínua a eles associados.

\section{Questões, fundamentos e proposições}


Ao longo dos anos, a Educação Física passou por profundas transformações, porém seu papel na escola ainda é bastante questionado, o que expõe o componente curricular a um movimento de tensões, de construções e reconstruções.

Herdeira de um processo histórico permeado de ideais conservadores, utilitaristas, no qual foi vista como uma atividade corporal, a Educação Física até hoje enfrenta problemas para ressignificar o seu papel a partir de uma visão na qual o estudante seja compreendido de forma integral, e demarcando objetivos no currículo vinculados a uma perspectiva crítica e democrática de educação (BRACHT, 1999).

Desde a sua inserção no ambiente escolar, a Educação Física assumiu diversas visões enquanto prática curricular na escola. De acordo com Soares (2001), alicerçou-se em aspectos biológicos e/ou tecnicistas e, por longos anos, teve como objetivo educar para o cuidado e disciplina do corpo. Diante disso, a autora pondera a respeito dessa adequação da Educação Física no processo de formação das relações sociais, que assim como outras ciências foram empregadas no sentido de ordenar e disciplinar os sujeitos, para que eles pudessem vir a contribuir dentro da nova sociedade que se esperava.

Opondo-se a essa condição e na perspectiva de legitimá-la na escola com objetivos pautados numa visão política e crítica da realidade, alguns autores elegeram como objeto de estudo da Educação Física: “O conjunto de práticas corporais construídas historicamente pelo homem em tempos e espaços determinados historicamente, sistematizadas ou não, que são passadas de geração em geração" (TAFFAREL et al., 2005, p. 03). Por essa ótica, a Educação Física é um componente curricular direcionado ao ensino de conteúdos selecionados do universo da cultura corporal e/ou, esportiva da humanidade (TAFFAREL; ESCOBAR, 2007).

Nesse sentido, a cultura corporal tratada na escola pública exprime uma compreensão de mundo na qual são estabelecidas relações dialéticas entre os objetivos do homem e as intenções da sociedade que se quer formar. Por isso, ela deve ser entendida como uma área de conhecimento construída sócio-historicamente pela atividade humana e ser apropriada por todos os sujeitos, pois é dever do poder público a promoção social da cultura, do esporte e do lazer como direito de todo sujeito (CRUZ; BARBOSA NETO, 2009).

Essa perspectiva de Educação Física requer uma construção coletiva alicerçada em espaços de formação contínua a partir de uma parceria constante entre universidade, por intermédio dos cursos de licenciatura, nesse caso específico, os cursos de licenciatura em Educação Física e a escola do ensino básico. Mediante uma via de mão dupla é possível que as concepções de sociedade, de escola e de ensino sejam colocadas permanentemente em questão, pois romper com a visão excessivamente biológica da área remete a investimentos nos cursos de formação inicial e contínua, por meio de diálogos entre a produção teórica, contexto escolar e práticas pedagógicas de ensino. De acordo com Vargas e Moreira (2012), é fundamental que se diminua a distância entre produção teórica e 
trabalho docente, pois as lacunas existentes entre a universidade e a escola parecem contribuir para uma distorção epistemológica da Educação Física.

Dessa maneira, a formação docente não se encerra na graduação, remete-se a um processo permanente, caracterizado pela busca incessante do conhecimento, que permite ao professor indagar o currículo, refletir acerca do seu posicionamento político e pedagógico e compreender o seu papel no âmbito escolar.

A formação docente é composta por inúmeras facetas, tem em sua essência a característica de ser dinâmica, guiada por fatores que influenciam diretamente o pensar e o fazer pedagógico. Nesse sentido, Tardif (2001) adverte que a formação docente deve considerar as peculiaridades sociais, econômicas, culturais, políticas e institucionais que interferem no trabalho do professor e no processo de ensino-aprendizagem.

A partir dessa compreensão, Pimenta (2002) registra a necessidade de formar profissionais capazes de intervir nos múltiplos contextos, considerando os conflitos e os dilemas neles imbricados. Para a autora, o processo da formação de professores é envolvido pela práxis pedagógica, de modo que, a teoria e a prática podem ser compreendidas como dimensões que, entrecruzadas, se completam no exercício docente, por meio da constante reflexão na ação e sobre a ação. A partir da práxis, vislumbra-se uma formação que possa romper com as persistentes condições de ensino e aprendizagem excludentes e construir práticas pedagógicas capazes de criar caminhos de emancipação e desenvolvimento social, cultural e humano no âmbito escolar (PIMENTA, 2000).

Com essa perspectiva, o subprojeto intitulado Educação Física na escola: fundamentos e propostas em uma perspectiva crítica respalda-se na constatação de que é preciso legitimar a Educação Física na escola por meio da efetivação de uma prática pedagógica alicerçada em princípios democráticos e de formação humana. Em outras palavras, uma Educação Física que veja o aluno para além dos seus aspectos biológicos, reconhecendo-o também como um ser social, político e cultural e que possa fomentar a eles uma leitura crítica de sua realidade (COLETIVO DE AUTORES, 1992).

Para isso, e com o entendimento de que se trata de um processo de investimentos formativos dialogados é que o curso de licenciatura de Educação Física da Uneb vislumbrou-se, através do Pibid, na possibilidade de fortalecimento e de contribuição para a ressignificação da área, pois, além de permitir uma interação reflexiva ao licenciando a partir de estudos e intervenção no chão da escola, promove também aos professores supervisores a avaliação da própria prática pedagógica. Nessa lógica construtiva foram dimensionados os processos de formação, bem como os limites e avanços que atravessam a área no contexto da prática pedagógica, no sentido de produzir conhecimentos significativos, fundamentados e politicamente comprometidos com os espaços acadêmicos e escolares.

As ações foram fundamentadas em referencial teórico de cunho crítico e contra-hegemônico, inspirado na Pedagogia Histórico-Crítica, proposta por Demerval Saviani, ao 
reconhecer a relação dialética entre educação e sociedade e a possibilidade do trabalho educativo, contribuindo para a transformação da realidade. Essa transformação requer a compreensão e a problematização das significações e da forma como a educação está organizada na sociedade, pois é a partir dela que o aluno pode perceber e interpretar as relações de poder e, consequentemente, refletir sobre sua prática e intervenção na sociedade (SAVIANI, 1995).

Com esse entendimento, a escola, a partir da Pedagogia Histórico-Crítica é vista como um espaço social de educação formal e de luta da classe trabalhadora. Por meio do acesso ao conhecimento sistematizado, a classe explorada terá condições de lutar contra o poder dominante e usufruir dos seus direitos, pois, segundo Saviani (1995), a escolarização é condição para que os sujeitos participem dos processos políticos e para a consolidação de uma sociedade socialmente justa.

Saviani (1980) ressalta que a democratização do ensino é basilar para o desenvolvimento do País, pois a educação é mediadora da prática social. Para o autor, a democracia escolar está alicerçada no acesso e na apropriação crítica do conhecimento por parte dos alunos. Assim, defende caminhos metodológicos que reconheçam os ritmos de aprendizagem e seu interesse. Em síntese, a Pedagogia Histórico-Crítica refere-se a um projeto de ensino escolar comprometido com a leitura crítica dos movimentos históricos, suas significações, conflitos, contradições, opressões, a fim de que o aluno possa compreendê-los e se mobilizar contra mecanismos excludentes na sociedade. $\mathrm{O}$ compromisso por parte dessa pedagogia articula o processo de ensino-aprendizagem aos processos de enfrentamento e superação das desigualdades no País.

O subprojeto foi orientado também pela Perspectiva Crítico-Superadora da Educação Física, uma proposta de ensino embasada no discurso da justiça social, na leitura crítica dos dados da realidade e na construção de caminhos para mudanças sociais. Essa perspectiva é viabilizada pela assimilação crítica da cultura corporal, fomentada pelo resgate histórico do conteúdo trabalhado e contestação dele com a conjuntura. $O$ desenvolvimento da noção de historicidade da cultura corporal é fundamental para a prática pedagógica da Educação Física, pois considera-se que é por meio da compreensão histórica do conhecimento que o aluno vai se reconhecer enquanto sujeito histórico capaz de intervir na realidade social, transformando-a (COLETIVO DE AUTORES, 1992).

Com base nos fundamentos da Pedagogia Histórico-Crítica e da perspectiva Crítico-Superadora, busca-se no âmbito da Educação Física a apropriação dos elementos da cultura corporal por uma ótica contra-hegemônica e de contribuição para a transformação da sociedade. Reporta-se sobre uma proposta pedagógica, que tem como intuito a superação da perspectiva tradicional, representada pelo modelo da aptidão física.

As práticas corporais por essas bases teóricas são entendidas como produto das relações humanas tecido por elementos sociais, econômicos, políticos e culturais. Assim, é papel da Educação Física escolar trabalhar com os conhecimentos sistematizados e 
acumulados sobre cultura corporal, buscando questionar suas significações ao longo da história, em prol de uma formação na qual o sujeito possa se conscientizar acerca de sua realidade e do seu papel diante dela. Por essa via, a aula é, portanto, um espaço intencionalmente organizado para possibilitar a apreensão, pelo aluno, do conhecimento específico da Educação Física e dos diversos aspectos das suas práticas na realidade social (COLETIVO DE AUTORES, 1992).

Para que isso aconteça, é necessário analisar a origem do conteúdo e conhecer o que determinou a necessidade de seu ensino. Outra perspectiva a ser considerada diz respeito à realidade material da escola, pois a apropriação do conhecimento da Educação Física supõe a adequação de instrumentos teóricos e práticos, tendo em vista que algumas habilidades corporais exigem, ademais, materiais específicos (COLETIVOS DE AUTORES, 1992).

\section{Os caminhos metodológicos}

Buscamos o relato de experiência que tem como intento refletir acerca dos espaços de formação contínua no âmbito do Pibid, a partir das ações e experiências viabilizadas pelo subprojeto desenvolvido entre agosto de 2018 a fevereiro de 2020 em três escolas de porte médio da Rede Municipal de Ensino de Guanambi/BA, por um grupo formado por um professor coordenador, 24 licenciandos que cursavam do primeiro ao quinto semestre, e três professoras efetivas do ensino básico.

O Pibid no Curso de Licenciatura em Educação Física, no Campus XII da UNEB, começou em 2012 com dez bolsistas de Iniciação à Docência (estudantes da licenciatura), duas bolsistas de supervisão (professoras da educação básica) e uma bolsista de coordenação (coordenadora de área, professora do ensino superior). Em 2014, houve uma ampliação no número de bolsistas, por meio de um novo edital e, em 2018, já em outro edital da Capes houve reestruturações na concepção de desenvolvimento do Subprojeto no referido curso.

Considerando as questões elencadas no item anterior pertinentes à Educação Física, à docência, às condições do programa e também às bases orientadoras do subprojeto, as ações foram organizadas em momentos que permitissem a compreensão teórico-crítica acerca de concepções de escola, de ensino, de Educação Física, bem como o confronto dessas questões com a realidade das escolas contempladas com o programa. Esses momentos foram desenvolvidos da seguinte forma:

1. Apresentação e discussão dos princípios orientadores do trabalho: trata-se de uma das primeiras etapas do Subprojeto, que teve como finalidade refletir sobre a proposta do programa, apresentar os objetivos e fundamentos do curso e orientar os bolsistas acerca das atividades a serem desenvolvidas. 
2. Familiarização do bolsista de iniciação à docência com o espaço escolar e a participação no desenvolvimento das práticas pedagógicas: essa etapa configurou-se com a aproximação dos bolsistas de iniciação à docência à realidade da escola, seguida pelo envolvimento dos licenciandos com as ações pedagógicas. Foi desenvolvida, semanalmente, de modo que os licenciandos, em dupla ou trio, acompanhavam duas aulas de Educação Física em uma mesma turma.

O primeiro momento foi direcionado para a observação do cotidiano das aulas, conhecendo o modo pelo qual, a escola, sobretudo, a Educação Física se organiza em relação às suas problemáticas, necessidades e expectativas. Essa estratégia inicial teve como objetivo fomentar aos bolsistas de iniciação à docência uma análise acerca da escola, dos seus enfrentamentos, especialmente daqueles pertinentes ao exercício docente e às singularidades das turmas e dos alunos, para que, em seguida, pudessem também contribuir com o desenvolvimento das atividades pedagógicas.

Já no segundo momento, além da observação das aulas, os alunos puderam construir e desenvolver ações pedagógicas coletivamente com os professores supervisores, logo, também vivenciar os desafios da docência no que se refere ao ato de ministrar aulas, considerando os seus objetivos, as particularidades dos alunos e as condições de trabalho.

Grupo de estudos: esse momento foi destinado a discussões acerca da base teórica do Subprojeto (Pedagogia Histórico-Crítica e Perspectiva Crítico-Superadora) e, também, sobre questões-problemas que envolvem a prática pedagógica, a Educação Física Escolar, a docência e a cultura corporal. Realizado, semanalmente, entre as professoras supervisoras, o professor coordenador e licenciandos, o grupo de estudos foi um espaço de encontros voltados para reflexões teóricas e, também, para a problematização de questões observadas e vivenciadas pelos envolvidos com o projeto. Essas reflexões tiveram como suporte teórico os seguintes livros: Escola e Democracia (2008) de Demerval Saviani, Uma Didática para a Pedagogia Histórico-Crítica, de João Luiz Gasparin (2009) e Metodologia do Ensino da Educação Física (1992), do Coletivo de Autores.

Avaliação: trata-se de um elemento que fez parte de todo o desenvolvimento das ações do subprojeto, através de momentos de escuta dos bolsistas de iniciação à docência, das professoras supervisoras, dos debates entre os envolvidos, das reflexões acerca das práticas pedagógicas, bem como dos espaços de conversas formais e informais com os alunos da escola. Contudo, ao encerrar as atividades, foi realizado um encontro com todos os bolsistas (coordenador, supervisoras, licenciandos), com o propósito de analisar o olhar dos envolvidos acerca do programa e, sobretudo, as lacunas e os avanços das atividades desenvolvidas.

\section{Os desdobramentos do Subprojeto}


Os espaços de diálogos, estudos, produções e avaliações das ações pedagógicas do Subprojeto de Educação Física, Campus XII, elencados no item anterior, envolveram um conjunto de questões que refletiram na formação de todos envolvidos.

Os momentos desenvolvidos pelo programa foram qualificados por um trabalho coletivo, com possibilidades de escuta, de trocas de informações, de socialização de estudos e de problematizações. Destacam-se, nos primeiros encontros, a angústia dos licenciandos em relação à identidade e o papel da Educação Física, bem como a exposição das professoras supervisoras acerca do espaço escolar, dos desafios enfrentados em relação à docência e ao componente curricular (Educação Física), como a inferiorização atribuída à área em relação aos demais componentes do currículo, falta de materiais, estrutura física inadequada das escolas, desmotivação e, algumas vezes, o comportamento inadequado dos alunos durante as aulas.

A partir da inserção dos licenciandos na escola e da participação deles na articulação das ações pedagógicas, a problematização sobre tais questões foi ampliada e intensificada. Buscou-se nos encontros semanais refletir sobre o olhar dos bolsistas de iniciação à docência acerca do contexto escolar, dialogando com a função social da escola, perante as contradições políticas, sociais e culturais da sociedade, tendo como base a Pedagogia Histórico-Crítica e Perspectiva Crítico-Superadora.

O intuito dessas reflexões foi fomentar uma leitura crítica acerca das demandas da escola e do componente curricular em estudo, estimulando a construção de caminhos pedagógicos que pudessem favorecer a ressignificação da Educação Física escolar alicerçada numa perspectiva crítica e democrática de educação.

Esse movimento foi permeado por diversos desafios. Alguns deles, normalmente associados ao processo de aprendizado e outros consequentes de problemas enfrentados pelas instituições educativas. Para o desenvolvimento das ações do Subprojeto, os envolvidos precisaram compreender a base orientadora dele, o que exigiu leituras e avaliações cuidadosas e, por diversas vezes, a reconstrução da prática pedagógica, considerando a estrutura física inadequada das escolas e a indisponibilidade de materiais pedagógicos.

Após o desenvolvimento das ações pedagógicas, os envolvidos no programa, principalmente os bolsistas de Iniciação à Docência e os professores supervisores reuniam-se para avaliá-las. Caso a atividade não tivesse um resultado satisfatório por rejeição dos alunos ou pouca compreensão da questão abordada, buscavam-se outros caminhos metodológicos possíveis, a partir das condições materiais e estrutura física das escolas.

Nesses espaços de debates, de questionamentos e de um novo olhar para a prática pedagógica da Educação Física, os professores supervisores que atuam no acompanhamento dos bolsistas de iniciação à docência tiveram a oportunidade de refletir coletivamente sobre suas angústias, seus anseios e também de pensar sobre seu posicionamento e condução das ações pedagógicas. 
Tais esforços representaram uma continuidade na formação docente dos professores supervisores, mesmo não sendo o principal objetivo do programa. A formação contínua, embora um direito assegurado aos profissionais da educação, possui inúmeras barreiras que lhes impedem de continuar os estudos. A maioria não tem condições de acesso e/ou de permanência, o que fragiliza o trabalho e caracteriza um empecilho à qualidade da educação brasileira.

Tendo em vista a carência de cursos de formação continuada no Brasil, sobretudo no campo da Educação Física, principalmente no âmbito escolar, com a dificuldade de afastamento remunerado do trabalho, os professores desta área dificilmente têm oportunidade de dar continuidade aos estudos, situação vivenciada pelas professoras supervisoras do Subprojeto de Educação Física da Uneb de Guanambi, BA. Uma delas cursa mestrado em educação na Universidade Estadual do Sudoeste da Bahia (Uesb), Campus Vitória da Conquista, mas o curso não é voltado para o estudo das questões pertinentes à Educação Física, mas da educação de modo geral.

Além desses problemas, os cursos de formação contínua, quando são ofertados aos docentes do ensino básico, muitas vezes são improvisados e desarticulados dos problemas vivenciados por estes profissionais no contexto escolar, sendo apenas investimentos direcionados ao fomento do mercado, a partir da oferta de cursos aligeirados (MOREIRA, 2002).

De acordo com Gadotti (2011), a formação continuada do professor deve ser arquitetada por mecanismos que estimulem a reflexão crítica sobre a prática e não como mera aprendizagem de técnicas ou a partir da atualização de receitas pedagógicas.

A formação continuada do professor deve ser concebida como reflexão, pesquisa, ação, descoberta, organização, fundamentação, revisão e construção teórica e não como mera aprendizagem de novas técnicas, atualização em novas receitas pedagógicas ou aprendizagem das últimas inovações tecnológicas. A nova formação permanente, segundo essa concepção, inicia-se pela reflexão crítica sobre a prática (GADOTTI, 2011, p. 41).

A partir do apontamento do autor, a escola e a sala de aula tornam-se lócus de referência para a formação contínua. Nesses espaços, estão os problemas e os enfrentamentos vivenciados pelos professores, alunos, pais, gestores, coordenadores, logo, os estudos formativos não podem se desconectar da realidade escolar. E é possível interligar dialeticamente saberes adquiridos pela formação e pela experiência docente e, consequentemente, construir melhorias para o processo de ensino-aprendizagem e para o currículo escolar.

É nesse sentido que Freire (2001, p. 72) pontua que "a melhora da qualidade da educação implica a formação permanente dos educadores. E a formação permanente se funda na prática de analisar a prática". Para o autor, a qualidade da educação requer a formação contínua dos professores baseada no exercício de analisar criticamente a prática e voltada para a desconstrução da docência concebida como uma instrução de sujeitos. 
Entendendo a educação como um ato político, ele chama atenção para importância de o professor analisar o seu fazer, a partir de um movimento dinâmico, dialético, constante e sistematizado, para enfrentar e superar as dificuldades da realidade concreta e criar caminhos democráticos e de autonomia docente e discente.

Esta perspectiva de formação permite a reflexão acerca dos múltiplos contextos educacionais e estimula aos docentes práticas de autorreflexão e um posicionamento frente às produções de conhecimento e suas diferentes manifestações, o que pode lhes instigar a buscar sempre a construção de ações pedagógicas direcionadas para o pensamento crítico dos educandos.

O Pibid, com um arranjo caracterizado por estudos sobre e a partir da prática pedagógica, torna-se um espaço de formação contínua do professor do ensino básico. Ao agregar conhecimento, esse programa abre caminhos para o docente analisar criticamente sobre sua postura e construções pedagógicas, qualificando-as. Não se trata de uma formação centrada nos moldes da certificação, mas capaz de mobilizar o professor para pensar e estudar o ensino, instigando-o a se reconhecer como sujeito protagonista do processo de formação e de atuação.

As trocas de experiências, os questionamentos e os estudos compartilhados no âmbito do Subprojeto de Educação Física da Uneb, Campus XII, que teve como objetivo construir coletivamente caminhos direcionados à ressignificação do papel deste componente curricular, nos impulsionaram a refletir, na condição de docentes, acerca da atual conjuntura política e do papel da Educação Física na escola, considerando seus princípios legais e, sobretudo, os alunos enquanto sujeitos de direitos.

Nesse processo, diversas indagações surgiam como propulsoras das discussões e conversas ou decorrentes delas, como: "o que podemos fazer para qualificar essa aula? Nossas práticas estão sendo coerentes ou não? Quais questões precisam ser repensadas no âmbito da educação básica e da formação inicial?"

As discussões sempre direcionavam para as dificuldades enfrentadas pela Educação Física ao longo de sua história, assim, a busca de uma resposta não foi uma tarefa fácil, pois abalava os posicionamentos políticos pedagógicos em relação ao lugar e ao papel do componente no currículo, cujas tensões envolvem fragilidades históricas, posturas docentes, desvalorização da área, fragilidades nos programas de formação, carência de políticas públicas direcionadas à educação etc.. Contudo, manter essas questões vivas é condição elementar para a construção de ações que fomentem uma Educação Física Crítica na escola e também para que os licenciandos compreendam o trabalho docente e suas condições nas escolas do ensino básico, como foi proposto pelo Subprojeto e pelo Pibid.

Acredita-se que a parceria entre os cursos de licenciatura e as escolas do ensino básico através do Pibid vem resultando em impactos significativos, tanto para os licenciandos, quanto para os professores atuantes como supervisor do programa, o que pode repercutir positivamente para a área de intervenção. Portanto, defende-se a permanência 
e ampliação do programa para que tais esforços possam ser qualificados e novos projetos possam ser traçados em prol de escolas e de uma Educação Física crítica e democrática.

\section{Algumas considerações}

Embora o Programa não seja direcionado à formação contínua de professores do ensino básico, considera-se que os momentos de reflexão, de estudos, debates e conversas viabilizadas pelas atividades deliberadas por ele foram significativos para a formação desses profissionais ao fomentar a análise crítica e reflexiva acerca da realidade escolar, das condições do componente no currículo e das práticas pedagógicas. Mesmo com algumas dificuldades relacionadas à carga horária alta dos professores envolvidos e a estrutura curricular do curso de licenciatura de Educação Física, o que implicou em uma rotatividade dos bolsistas de Iniciação à Docência, o diálogo entre universidade e escola do ensino básico foi significativo para os participantes, inclusive para o professor supervisor.

Considerando a importância do Pibid nesse aspecto, acredita-se que o programa precisa se tornar permanente nos cursos de licenciatura, a partir de uma perspectiva de ampliação e de qualificação das ações, para que mais estudantes e professores do ensino básico possam ser contemplados e, também, para que novas ações sejam arquitetadas.

Além disso, analisa-se como emergente que a lógica de organização e de intervenção do Pibid seja fomentada e adotada pelos programas direcionados à formação contínua de professores, sobretudo, daqueles da área de Educação Física, tendo em vista os problemas identitários da área, pois a produção do conhecimento escolar não pode ser dissociada do chão da escola, de suas demandas e de seus enfrentamentos diários. Essa condição é categórica para a melhoria da qualidade da educação brasileira, quando pensada enquanto um direito social dos sujeitos, bem como para a reconstrução do papel da Educação Física na escola.

Vale ressaltar que, o fato de o Pibid vir abrindo espaços de formação para professores do ensino básico, não exime a responsabilidade do Estado de construir novas políticas voltadas à formação do docente em exercício, especialmente em nível de especialização (pós-graduação lato sensu) e mestrado e doutorado (stricto sensu). Para que realmente haja ressignificação da Educação Física, faz-se necessário atentar para o processo de formação docente, no sentido de fazer com que os professores reflitam de forma ininterrupta acerca da realidade do componente curricular, reconhecendo-se nesse processo de lutas. Isso reivindica o diálogo entre o espaço acadêmico e o cotidiano escolar, para que os enfrentamentos pertinentes ao trabalho pedagógico sejam debatidos coletivamente a partir da realidade das escolas e de forma aprofundada.

Portanto, em prol da melhoria da educação brasileira e de uma compreensão mais detalhada acerca das contribuições do Pibid para a formação contínua de professores 
supervisores, bem como de outros aspectos no âmbito do programa, é de fundamental importância a realização de estudos abrangendo todos os sujeitos e instituições envolvidos (estudantes e escolas do ensino básico, bolsistas de iniciação à docência, professores supervisores, coordenadores etc.). A análise dos impactos desse programa na formação de professores e no ensino contribui para que esforços sejam somados em defesa de uma educação pública, gratuita, laica e de qualidade, pois diante de um cenário em que projetos acríticos estão sendo potencializados no País, é basilar um olhar constante e crítico acerca dos espaços de formação frente aos movimentos que os ameaçam.

Recebido em: 16/09/2020 e Aprovado em: 12/11/2020

\section{Referências}

BAGNARA, Ivan Carlos. Educação Física Escolar e os Processos de Formação Continuada. Rev. Bras. Ciênc. Esporte, Florianópolis, v. 36, n. 2, supl., p. S413-S427, abr./jun. 2014.

BRACHT, Valter. A constituição das teorias pedagógicas da educação física. Cadernos CEDES, Campinas, v. 19 n. 48, aug. 1999.

BRASIL. Portaria CAPES no 175 de 07 de agosto de 2018. Regulamenta a concessão de bolsas e o regime de colaboração no Programa de Residência Pedagógica e no Programa Institucional de Bolsa de Iniciação à Docência - PIBID. Diário Oficial da União. 7 de agosto de 2018.

COLETIVO DE AUTORES. Metodologia do Ensino da Educação Física. São Paulo, Cortez, 1992.

CRUZ, Marlon Messias Santana. BARBOSA NETO, João Narciso. A relação dialética a educação inclusiva na atual conjuntura social. In: Lecturas EF y Deportes: revista digital. Buenos Aires. Ano 14. n. 131, 2009. Disponível em: http://www.efdeportes.com/efd131/a-relacao-dialetica-da-educacao-inclusiva-naatual-conjuntura-social.html. Acesso em 28 de agosto de 2020.

FREIRE, Paulo. Política e educação: ensaios. 6a ed. São Paulo: Cortez, 2001. (Org. e notas de Ana Maria Araújo Freire).

GADOTTI, Moacir. Boniteza de um sonho: ensinar-e-aprender com sentido. 2. ed. São Paulo: Instituto Paulo Freire, 2011.

MOREIRA, Carlos Eduardo. Formação continuada de professores: entre o improviso e a profissionalização. Florianópolis: Insular, 2002.

PASSOS, Carmensita Matos Braga. PIBID e Formação Docente: construindo possibilidades. EdUECE, 2014. Disponível em: http://www.uece.br/endipe2014/ebooks/livro4/21.\%20 CONTRIBUI\%C3\%87\%C3\%95ES\%20DO\%20PIBID \%20PARA $\% 20 \mathrm{~A} \% 20$ FORMA $\%$ C3\%87\%C3\%83O $\% 20$ DE\%20PROFESSORES.pdf Acesso em: 24 de outubro de 2020.

PIMENTA, Selma Garrido. A pesquisa em didática - 1996 a 1999. In: CANDAU, V. M. (Org.), Didática, currículo e saberes escolares. Rio de Janeiro:DP\&A, 2000. 
PIMENTA, Selma Garrido. "Professor reflexivo: construindo uma crítica". In: PIMENTA, Selma Garrido; GHEDIN, Evandro. Professor reflexivo no Brasil: gênese e crítica de um conceito. São Paulo: Cortez, 2002.

SAVIANI, Demerval. Educação: do senso comum à consciência filosófica. São Paulo: Cortez/Autores Associados, 1980.

SAVIANI, Demerval. Escola e democracia. Campinas: Autores Associados, 1995.

SOARES, Carmen Lúcia. Educação Física: raízes europeias e Brasil. 2.ed. SP: Autores associados (coleção educação contemporânea), 2001.

TAFFAREL, Celi Nelza Zulke; et al. Cultura corporal e território: uma contribuição ao debate sobre reconceptualização curricular. Motrivizência, Florianópolis, ano XVII, n. 25, p. 17-35, 2005. Disponível em: https://periodicos.ufsc.br/index.php/motrivivencia/article/view/4693/3870. Acesso em: 15 de agosto de 2020.

TAFFAREL, Celi Zulke; ESCOBAR, Micheli Ortega. Mas, afinal, o que é Educação Física: reafirmando o marxismo contra o simplismo intelectual. In: Rascunho Digital, 2007. Disponível em: http://www.faced. ufba.br/rascunho_digital. Acesso em 15 de agosto 2020.

TARDIF, Maurice. Saberes Docentes e Formação Profissional. Petrópolis, RJ: Vozes, 2001.

VARGAS, Cláudio Pellini; MOREIRA, Antonio Flavio Barbosa. A Crise Epistemológica na Educação Física: implicações no trabalho docente. Cadernos de Pesquisa, São Paulo, v. 42 n. 146 p. 408-427, mai./ago. 2012.

VERGOPOLAN, Roseli; MATTOS, Luciane Maria Serrer de. PIBID e a Formação continuada: relatos, percepções e aprendizagens na educação básica. Anais do XI Congresso Nacional de Educação (EDUCERE). Pontifícia Universidade Católica do Paraná. Curitiba, 2013. 